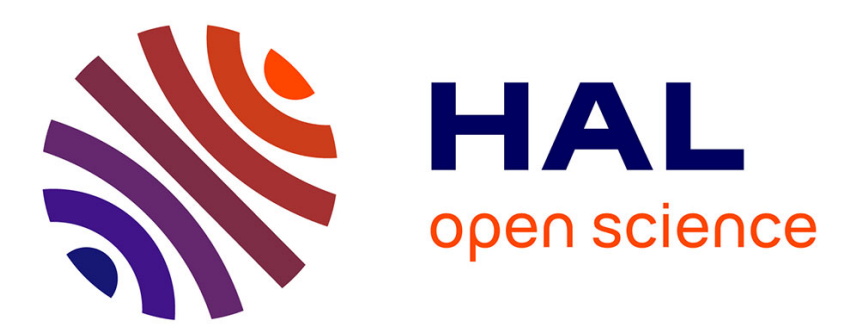

\title{
Study on Simulation of Rice Yield with WOFOST in Heilongjiang Province
}

\author{
Shangjie Ma, Zhiyuan Pei, Yajuan He
}

\section{To cite this version:}

Shangjie Ma, Zhiyuan Pei, Yajuan He. Study on Simulation of Rice Yield with WOFOST in Heilongjiang Province. 10th International Conference on Computer and Computing Technologies in Agriculture (CCTA), Oct 2016, Dongying, China. pp.40-51, 10.1007/978-3-030-06155-5_5 . hal02179975

\section{HAL Id: hal-02179975 \\ https://hal.inria.fr/hal-02179975}

Submitted on 12 Jul 2019

HAL is a multi-disciplinary open access archive for the deposit and dissemination of scientific research documents, whether they are published or not. The documents may come from teaching and research institutions in France or abroad, or from public or private research centers.
L'archive ouverte pluridisciplinaire HAL, est destinée au dépôt et à la diffusion de documents scientifiques de niveau recherche, publiés ou non, émanant des établissements d'enseignement et de recherche français ou étrangers, des laboratoires publics ou privés. 


\title{
Study on Simulation of Rice Yield with WOFOST in Heilongjiang Province
}

\author{
Shangjie Ma ${ }^{1,2}$, Zhiyuan Pei ${ }^{1,2(\bowtie)}$,Yajuan $\mathrm{He}^{1,2}$ \\ ${ }^{1}$ Key Laboratory of Cultivated Land Use, Ministry of Agriculture, P. R. China, Beijing, \\ China \\ ${ }^{2}$ Chinese Academy of Agricultural Engineering, Beijing, China; \\ peizhiyuan@agri.gov.cn
}

\begin{abstract}
WOFOST(world food study) model had been successfully used in daily business of agro meteorological monitoring and yield forecasting in European Union, and also been widely used in crop growth process simulation and yield estimation all over the world. In this study, with the help of the rice growth observed data, the meteorological data at the same time and the rice planting regional planning data in Heilongjiang Province, the crop parameters for WOFOST model were improved. Based on the localization and regionalization of the model, the rice yield in county and region scale in Heilongjiang Province was simulated. In province scale, the WOFOST simulated yield was good, and the relative error between estimated yield and statistical yield from 2006 to 2013 were respectively $2.71 \%, 8.47 \%, 6.41 \%$, $15.96 \%, 3.95 \%, 0.02 \%,-7.06 \%, 0.88 \%$, four of which beyond $\pm 5 \%$. But in county scale, the correlation between WOFOST simulated and statistical yield was poor, and not passing the test of significance. In order to improve the precision, the trend yield calculated by the statistical yield and the WOFOST simulated yield were both used to build a comprehensive rice yield simulation model by the multiple linear regression method year by year from 2006 to 2013. Then the rice yield both in county and province scale in Heilongjiang Province was calculated by using the comprehensive model. In county scale, the comprehensive simulated yield and the statistical yield in county scale passed significant test of 0.01 , and the correlation coefficients were respectively 0.715 , $0.728,0.829,0.810,0.888,0.919,0.868,0.798$, the R2 were respectively 0.511 , $0.529,0.686,0.656,0.789,0.844,0.753,0.636$. In province scale, the relative error between the estimated yield and statistical yield during 2006-2013 were respectively $-1.72 \%, 2.12 \%, 3.02 \%,-2.45 \%, 1.27 \%,-0.89 \%,-0.38 \%, 1.96 \%$. The comprehensive model had a good effect on improving the defects of fluctuation in individual year with a relative higher accuracy than that of only using WOFOST model, and could satisfy the application of rice yield estimation in large region.
\end{abstract}

Keywords: WOFOST, Rice Yield, Heilongjiang Province

\section{$1 \quad$ Introduction}

Rice is the largest cultivated area and highest total yield ration grain in China and plays an important role in the grain producing. Rice yield estimation is very important for the rice production and food security in China. Driving by the light, temperature, water, soil and other environmental variables, the crop growth dynamic model can daily simulate the photosynthesis, respiration, transpiration and evaporation process in crop growth period, and their relationship with meteorological, soil, and other 
environmental conditions, and can quantitatively describe the dynamic process of crop growth, development, and yield information. WOFOST model originated in the framework of interdisciplinary studies on world food security and on the potential world food production by the Center for World Food Studies in cooperation with the Wageningen Agricultural University ${ }^{[1]}$. WOFOST is a mechanism model, and can be used in crop growth monitoring and evaluating, crop yield forecasting, estimating the regional crop production, the influence assessment of disasters, and so on. For example, the model had been successfully used in daily business of agro meteorological monitoring and yield forecasting in European Union ${ }^{[2]}$. Meanwhile, WOFOST was also widely used in board as follows. Wu Dingrong ${ }^{[3]}$ evaluated the applicability of WOFOST in the North China Plain. Xie Wenxia ${ }^{[4]}$ simulated and validated the rice potential growth process in Zhejiang Province by utilizing WOFOST. According to climate characteristic and ecologic type of winter wheat variety in North China, Ma Yuping ${ }^{[1]}$ adjusted the parameters of WOFOST, and simulated phenological phase of overwinter in the region. Chen Zhenlin ${ }^{[5]}$ simulated the integrated impacts of low temperature and drought on maize yield. The abovementioned applications were in field scale. Combining the GIS technology, the application of WOFOST can be extended to regional scale. Ma Yuping ${ }^{[6]}$ simulated the winter wheat growth in regional scale in North China Plain by scaling-up WOFOST model. Li Xiufen ${ }^{[7]}$ evaluated the suitability of meteorological conditions during growing period of Maize in northeast of China. Gao Yonggang ${ }^{[8]}$ divided the model parameters into different fitting parts for the four main crops and the yield of four main crops were simulated and analyzed in Heilongjiang Province, by the synthesis regression equations with the predicted yields by WOFOST model and the trend yields. Du Chunying ${ }^{[9]}$ used the Heilongjiang Province rice growth observed data ( development period, biomass, grow variety, ripe type) and contemporary meteorological data, combined with local actual grow situation, divided the WOFOST model rice being suitable area, improved original growth parameter, carried out WOFOST model dynamic application on Heilongjiang Province rice growth simulation. Wang Yuguang ${ }^{[10]}$ used the CGMS(Crop Growth Monitoring System) to forecast the crop production in Heilongjiang Province. Bai Mingqi ${ }^{[11]}$ used the daily observed meteorological data from 1961 to 2003, the WOFOST model and the climate change trend analysis method, analyzed the influence of temperature on rice yield changing. However, there were few reports about the estimating the rice yield both in county and province scale by using the comprehensive rice yield simulation model which was estimated by the trend yield calculated by the statistical yield and the WOFOST simulated yield.

In this paper, the Heilongjiang Province rice growth observed data, contemporary observed meteorological data, and the local actual grow situation were all used to improve the rice parameter in WOFOST and simulated the rice yield in Heilongjiang Province. Combining the trend yield and WOFOST simulated yield, the comprehensive rice yield simulation model was estimated in Heilongjiang from 2006 to 2013 year by year. The simulation results were verified both in county and province scale. All these would provide the basis for regional crop yield estimation by using crop growth model.

\section{Materials And Methods}

\subsection{Study Area}

Heilongjiang Province locates between $121^{\circ} 11^{\prime} \mathrm{E} \sim 135^{\circ} 05^{\prime} \mathrm{E}$ and $43^{\circ} 26^{\prime} \mathrm{N} \sim 53^{\circ} 33^{\prime} \mathrm{N}$, in the Northeast of China. The total area of the province is about $454000 \mathrm{~km}^{2}$. Northeast of the Sanjiang Plain and west of the Songnen Plain were part of China's largest area plain, the Dongbei Plain. The area of plain accounts for 37 percentage of the total area of the province. The province lies in the cold temperate region and warm temperate region, and belongs to temperate continental monsoon climate, with annual 
average temperature in $-4 \sim 5^{\circ} \mathrm{C}$. The daily difference between maximum and minimum temperature is $10 \sim 14^{\circ} \mathrm{C}$ in May-September. The accumulated temperature greater than or equal $10^{\circ} \mathrm{C}$ is $2100 \sim 2900^{\circ} \mathrm{C}$. The annual sunshine duration is 2300 2900 hours and the annual efficient solar radiation is $218 \sim 230 \mathrm{KJ} / \mathrm{cm}^{2}$, with the average efficient solar radiation in April-September $155 \mathrm{KJ} / \mathrm{cm}^{2}$. The average annual rainfall is between 400 and $700 \mathrm{~mm}$, and most of them is in June-August. The province is one of the main grain production bases in China, and the main crops include spring maize, rice and soybean. According to climate characteristics, ecological condition, geographical distribution and so on, the whole rice planting region in Heilongjiang Province can be divided into 3 planting districts warm and 5 planting sub-districts ${ }^{[12]}$ (see figure1). The 3 districts are respectively southern warm humid rice planting district, the middle temperate semi-humid and western warm semi-arid rice planting district, and the northern cold rice planting district. And the middle temperate semi-humid and western warm semi-arid rice planting district can be divided into the middle temperate semi-humid rice planting sub-district and the western warm semi-arid rice planting sub-district. The northern cold rice planting district can be divided into the humid cold rice planting sub-district and the arid cold rice planting sub-district.

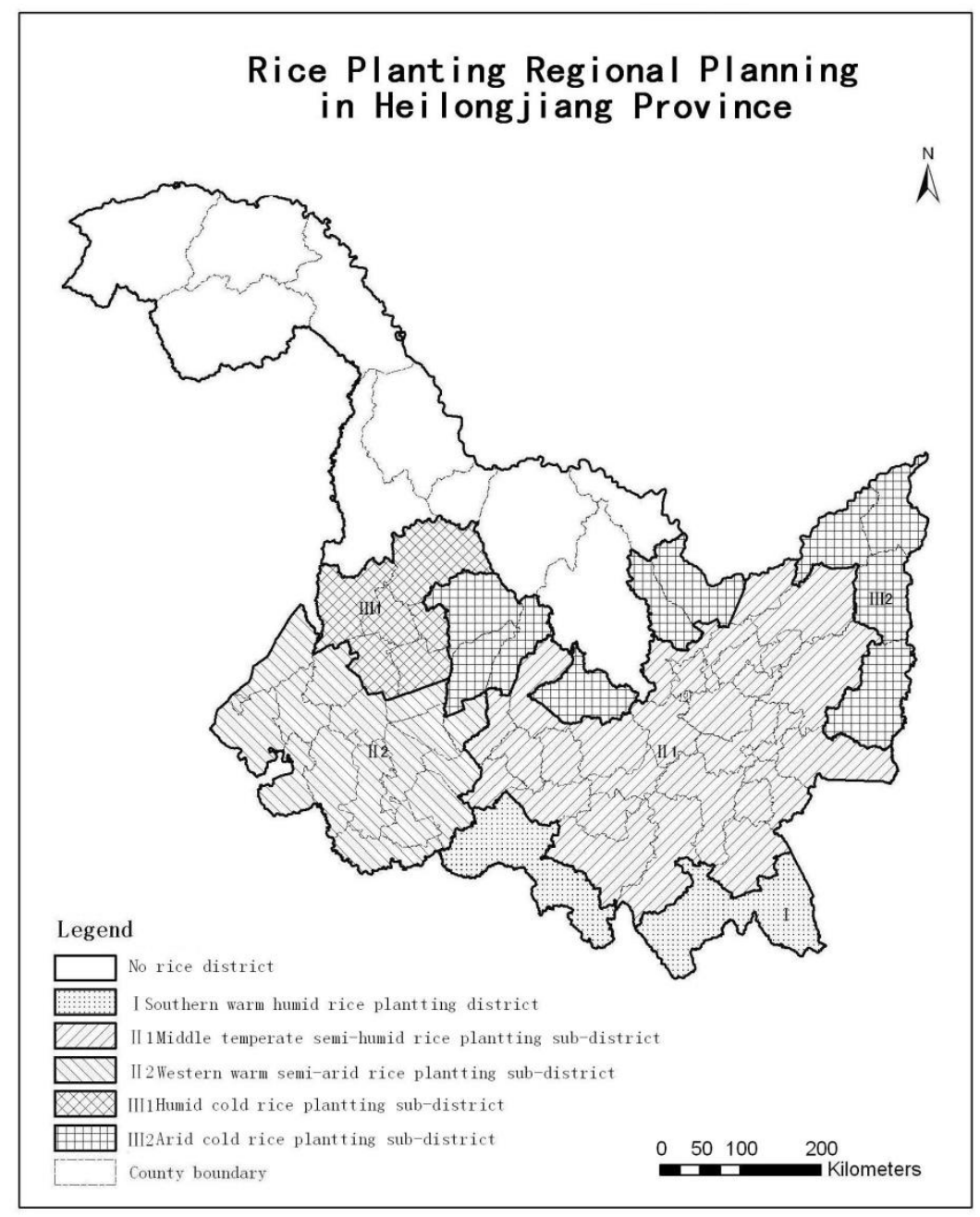

Fig. 1. Rice planting regional planning in Heilongjiang province

\subsection{Data Acquisition And Processing}

The every ten days rice growth condition observed data from 9 Agricultural Meteorological Stations in Heilongjiang Province from 2000 to 2013, including the phenological phase name and date, the date anomalies, the accumulated temperature from sowing to the current ten days and so on, was downloaded from the China 
Meteorological Data Sharing Service System ${ }^{[13]}$. The daily observed Meteorological data from 35 National Basic Meteorological Stations in Heilongjiang Province at the same time, including maximum temperature, minimum temperature, precipitation, sunshine duration, average wind speed, atmosphere pressure, relative humidity, and so on, was also downloaded from the website. The other needed parameters, water vapor pressure, solar radiation, and transpiration which had no observed data, could be calculated. The water vapor was calculated by relative humidity multiplying the saturation vapor pressure. The saturation vapor pressure was calculated by the formula recommended by China Meteorological Administration ${ }^{[14]}$. The solar radiation and transpiration were calculated respectively by Ångström Equation and Penman Formula ${ }^{[15]}$. Harmonized World Soil Database from Food and Agricultural Organization of the United Nations ${ }^{[16]}$ was collected to create the soil parameter set for the model. The map of soil spatial distribution was extracted from the soil database of FAO. The most physical and chemical properties referred to that in model, and the important parameters, such as field capacity, saturated water content, wilting coefficient, were calculated by SPAM (soil-plant-atmosphere-water) using the texture, organic matter content from the soil database of $\mathrm{FAO}^{[17]}$. The map of rice planting area spatial distribution in Heilongjiang Province in 2007 produced by the Remote Sensing Application Center of Ministry of Agriculture was used(see figure2). The rice area, yield, and total production statistic data in counties in Heilongjiang Province from 2000 to 2013 was also collected.

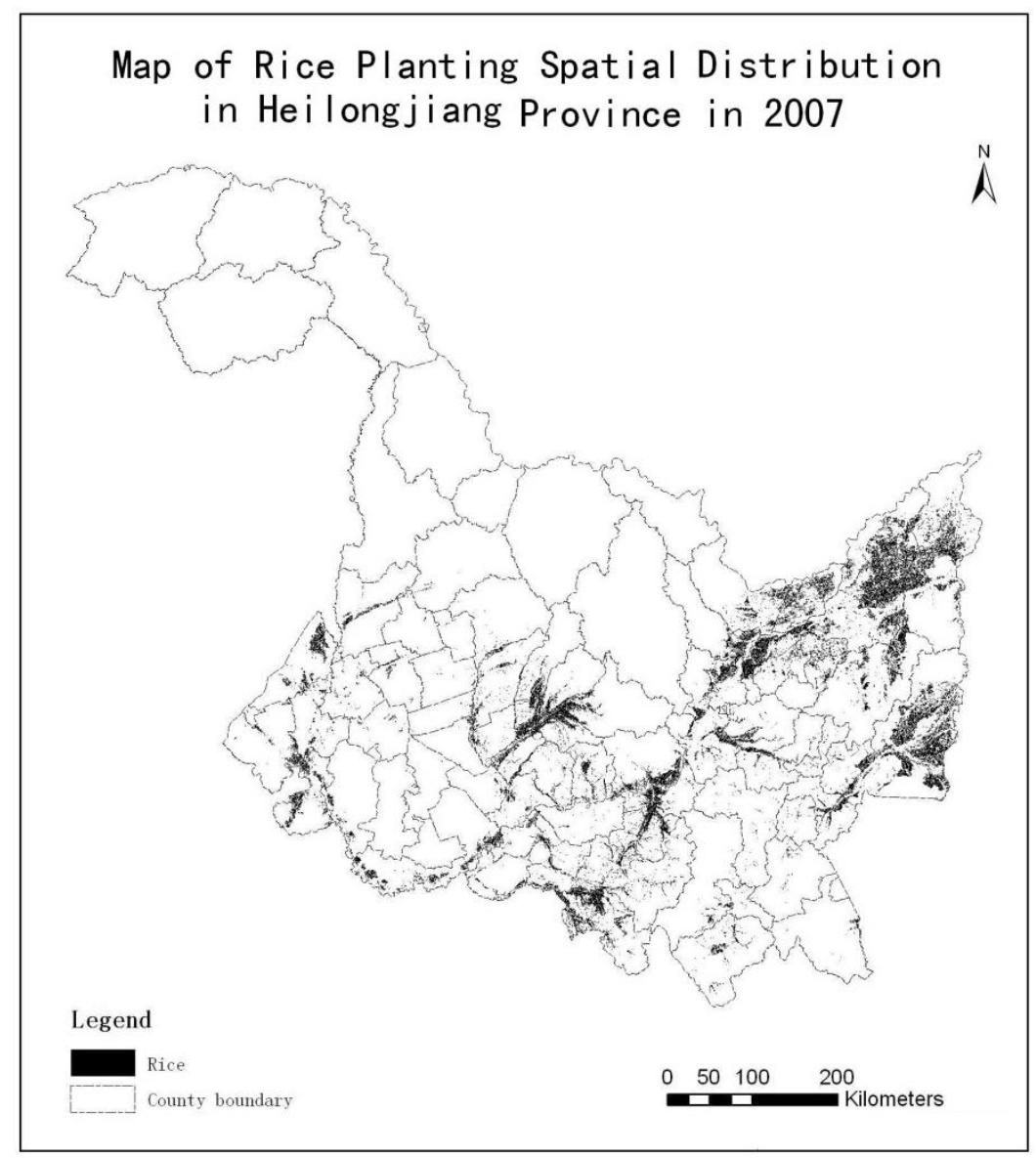

Fig. 2. Map of Rice planting spatial distribution in Heilongjiang province in 2007 


\subsection{Model Localization}

\subsubsection{Model Introduction}

In the WOFOST model, temperature is the main driving factor affecting the rice growth and development. So the accumulated temperature method was used to calculate the phenological phase of the rice by the formula as below.

$\mathrm{D}_{\mathrm{rt}}=\frac{\mathrm{T}_{\mathrm{ei}}}{\mathrm{TSUM}_{\mathrm{j}}}(\mathrm{j}=1,2)$
$\left\{\begin{array}{c}\mathrm{T}_{\mathrm{ei}}=0, \mathrm{~T}_{\mathrm{i}} \leq \mathrm{T}_{\mathrm{b}} \\ \mathrm{T}_{\mathrm{ei}}=\mathrm{T}_{\mathrm{i}}-\mathrm{T}_{\mathrm{b}}, \quad \mathrm{T}_{\mathrm{b}}<\mathrm{T}_{\mathrm{i}}<\mathrm{T}_{\text {max }} \\ \mathrm{T}_{\mathrm{ei}}=\mathrm{T}_{\text {max }}-\mathrm{T}_{\mathrm{b}}, \quad \mathrm{T}_{\mathrm{i}} \geq \mathrm{T}_{\text {max }}\end{array}\right.$

In which, $D_{r t}$ is the growth speed at $t$ moment $\left(\mathrm{d}^{-1}\right), T_{e i}$ is the daily efficient temperature $\left({ }^{\circ} \mathrm{C}\right), \operatorname{TSUM}_{\mathrm{j}}(\mathrm{j}=1,2)$ is the efficient accumulated temperature required to pass to the next development stage $\left({ }^{\circ} \mathrm{C} \cdot \mathrm{d}\right), \mathrm{T}_{\mathrm{i}}$ is the daily average temperature $\left({ }^{\circ} \mathrm{C}\right), \mathrm{T}_{\mathrm{b}}$ is the base temperature below which no development occurs $\left({ }^{\circ} \mathrm{C}\right), \mathrm{T}_{\max }$ is the maximum effective temperature above which no development occurs $\left({ }^{\circ} \mathrm{C}\right)$, and the crop development stage(DVS) can be described as follows,

DVS $=\frac{\int \mathrm{T}_{\mathrm{ei}}}{\mathrm{TSUM}_{\mathrm{j}}}$

WOFOST uses DVS to define the crop physiological age, and for the rice, DVS respectively equal 0 in the seeding stage, 0.65 in the booting stage, 1.0 in the anthesis stage, and 2.0 in the mature stage.

The regional yield simulation model in WOFOST uses the following formula,

$\mathrm{Y}_{\mathrm{T} 2}=\frac{\sum_{\mathrm{i}=1}^{\mathrm{n}}\left(\mathrm{C}_{\mathrm{ei}} \mathrm{A}_{\mathrm{ei}} \mathrm{Y}_{\mathrm{Tei}}\right)}{\sum_{\mathrm{i}=1}^{\mathrm{n}}\left(\mathrm{C}_{\mathrm{ei}} \mathrm{A}_{\mathrm{ei}}\right)}$

Where, $\mathrm{Y}_{\mathrm{T} 2}$ refers to the simulated yield in every county in $\mathrm{T}$ year $\left(\mathrm{t} / \mathrm{hm}^{2}\right)$, YTei is the simulated yield in NO.i EMU(The Elementary Mapping Unit) in T year $\left(t / \mathrm{hm}^{2}\right), \mathrm{A}_{\mathrm{ei}}$ is the area of the NO.i EMU $\left(\mathrm{hm}^{2}\right), \mathrm{C}_{\mathrm{ei}}$ is the proportion of a certain crop, and $\mathrm{n}$ is the number of EMUs in the county.

\subsubsection{Model Regionalization}

The whole province was divided into 244 grids, each of which $50 \mathrm{~km} \times 50 \mathrm{~km}$. The daily observed data with 9 parameters, was interpolated to the grids. The annual average dates of the three key phonological stages, including the transplanting stage, the anthesis stage, and the mature stage, were calculated firstly by using the data from 9 Agricultural Meteorological Stations during 2000-2013. Then, the station dates were interpolated into the grids, becoming the grid dates. Next, the crop parameters TSUM1 and TSUM2 in each grid, which were respectively the efficient accumulated temperature required from the transplanting stage to the anthesis stage, and from the anthesis stage to the mature stage, were calculated by using the observed temperature and the average dates grid by grid. Based on the research results before ${ }^{[8]}$ and the rice planting regional planning in Heilongjiang province, 41 combinations of TBASE(the efficient accumulated temperature required from seeding to tranplating), TSUM1 and TSUM2 were attained. Overlayed the county boundary and the map of soil type spatial distribution, divided the whole province into a number of EMUs in which the combination of meteorology and soil type were homogeneous. After preparing the parameters of the WOFOST in each unit, the model was run in sequence. And so, the model was used in region. 
The trend yields represents the influence of long term economic and technological dynamics, the no meteorological factors, such as increased fertilizer application, improved crop management methods, new high yielding varieties, etc. on yield. Considering the influence of the no meteorological factors, both the trend yields and the WOFOST simulated yields were used to build the comprehensive rice yield simulation model. The trend yields from 2000 to the year before the simulated year, and the WOFOST simulated yields, in the 52 rice producing counties in the province, were analyzed by the method of multiple linear regression to build the comprehensive rice yield simulation model in Heilongjiang Province in 2006-2013 as follows.

$\mathrm{Y}_{\text {yield }}=\mathrm{A} \times \mathrm{Y}_{\text {trend }}+\mathrm{B} \times \mathrm{Y}_{\text {WOFOST }}+\mathrm{C}$,

in which, $\mathrm{Y}_{\text {yield }}$ was the comprehensive simulation yield, $\mathrm{Y}_{\text {trend }}$ was the trend yield which could be calculated by the statistical yield sliding average for five years ${ }^{[18]}$, YwoFost was the WOFOST simulation yield, and A, B, C were the coefficient.

Table 1. The comprehensive rice yield simulation model in 2006-2013

\begin{tabular}{llllllll}
\hline Year & Parameter A & Parameter B & Parameter C & $\mathrm{R}$ & $\mathrm{R}^{2}$ & Sig & $\mathrm{F}$ \\
\hline 2006 & 1.0112 & 0.1823 & -1423.8601 & 0.8384 & 0.7012 & 0.0000 & 435.2181 \\
2007 & 1.1383 & 0.2554 & -2588.9785 & 0.7957 & 0.6313 & 0.0000 & 363.2133 \\
2008 & 1.1217 & 0.2400 & -2384.7742 & 0.8030 & 0.6432 & 0.0000 & 430.1120 \\
2009 & 1.0846 & 0.2531 & -2259.1537 & 0.8004 & 0.6393 & 0.0000 & 469.8140 \\
2010 & 1.0725 & 0.2356 & -2068.1397 & 0.8083 & 0.6521 & 0.0000 & 546.5621 \\
2011 & 1.0784 & 0.2421 & -2116.8362 & 0.8153 & 0.6636 & 0.0000 & 627.3418 \\
2012 & 1.0717 & 0.2202 & -1843.0577 & 0.8090 & 0.6535 & 0.0000 & 649.8057 \\
2013 & 1.0747 & 0.2491 & -2213.0013 & 0.8514 & 0.7231 & 0.0000 & 414.8676 \\
\hline
\end{tabular}

\section{Results And Analysis}

The comprehensive yield simulation model was used to estimate the rice yield annually in county scale and province scale in Heilongjiang Province in 2006-2013. The result showed that, in county scale, the simulated yield and the statistical yield passed significant test of 0.01 , and the correlation coefficients were respectively 0.715 , $0.728,0.829,0.810,0.888,0.919,0.868,0.798$, the $\mathrm{R}^{2}$ were respectively $0.511,0.529$, $0.686,0.656,0.789,0.844,0.753,0.636$ (see figure 3 ). But the correlation between WOFOST simulated and statistical yield was poor, and not passing the test of significance(see figure4). This might be caused by the limitation of getting parameters, such as meteorology, crop, and management and so on, in big area while using the WOFOST model in regional scale. 

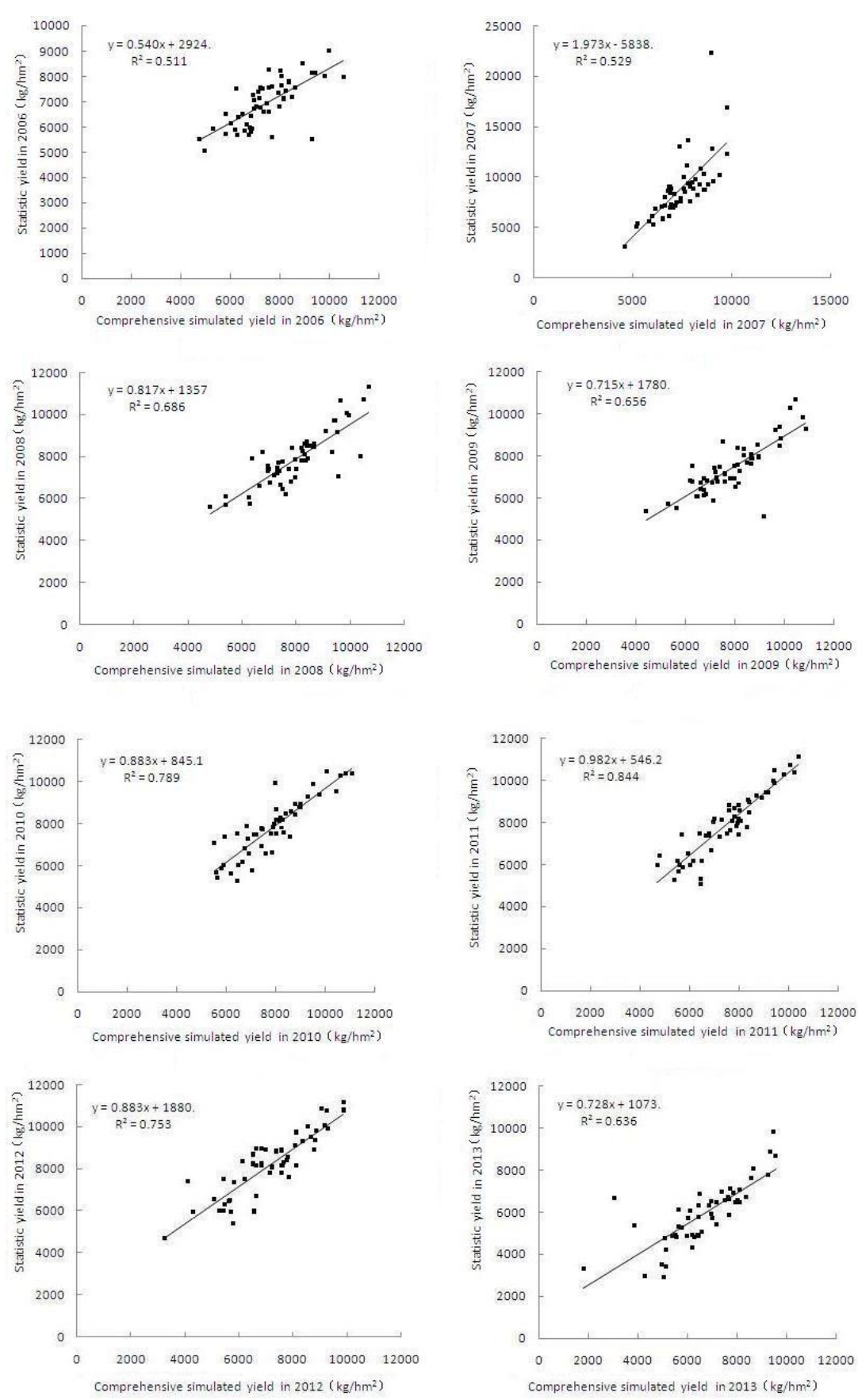

Fig. 3. Comparison of the comprehensive simulated yield and statistical yield at county scale in Heilongjiang Province from 2006 to 2013 

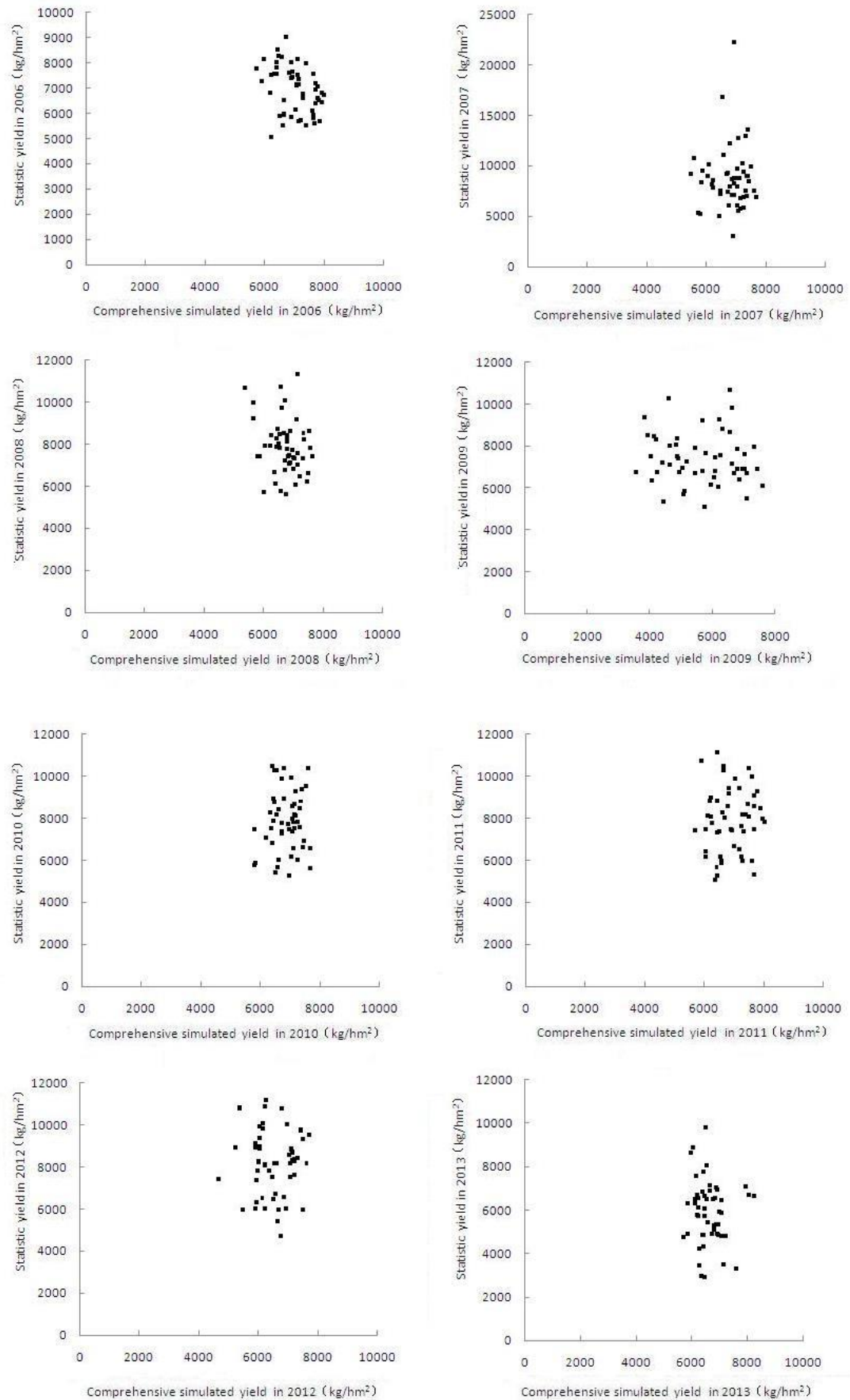

Fig. 4. Comparison of WOFOST yield and statistical yield at county scale in Heilongjiang Province from 2006 to 2013

In province scale, the comprehensive simulation yields during 2006-2013 were respectively 6709.07, 6426.28, 6541.3, 6241.68, 6744.42, 6938.33, 7045.89, 7130.04 $\mathrm{kg} / \mathrm{hm}^{2}$, and the statistical yields at the same time were respectively $6826.65,6292.8$, $6349.65,6398.25,6659.55,7000.65,7072.80,6993 \mathrm{~kg} / \mathrm{hm}^{2}$ (see figure5). The relative differences between the comprehensive simulation yield and the statistical yield during 2006-2013 were respectively $-1.72 \%, 2.12 \%, 3.02 \%,-2.45 \%, 1.27 \%,-0.89 \%$, $0.38 \%, 1.96 \%$. The change rates year by year of the comprehensive simulation yield were respectively $-4.22 \%, 1.79 \%,-4.58 \%, 8.05 \%, 2.86 \%, 1.55 \%, 1.19 \%$, and that of the statistical yields were respectively $-7.82 \%, 0.90 \%, 0.76 \%, 4.08 \%, 5.12 \%, 1.03 \%$, $1.13 \%$. And 5 of them had the same change trend, 2 of them had the opposite trend. The WOFOST simulated yields during 2006-2013 were respectively 7011.76, $6825.99,6756.44,5376.8,6922.44,7001.8,6573.2,7054.82 \mathrm{~kg} / \mathrm{hm}^{2}$, and the relative 
differences between the WOFOST simulated yields and the statistical yield during 2006-2013 were respectively $2.71 \%, 8.47 \%, 6.41 \%,-15.96 \%, 3.95 \%, 0.02 \%,-7.06 \%$, $0.88 \%$. The relative differences of $2007,2008,2009,2012$ were larger, more than $\pm 5 \%$. The change rates year by year of the WOFOST simualted yield were respectively $-2.65 \%,-1.02 \%,-20.42 \%, 28.75 \%, 1.15 \%,-6.12 \%, 7.33 \%$. And 3 of them had the same change trend, 4 of them had the opposite trend. The WOFOST simulated yield here had the defaults of big error and larger inter annual fluctuations in individual year. Being introduced the trend yields, the comprehensive simulation yields had a good effect on improving the defects above, and could satisfy the application of rice yield estimation in large region.

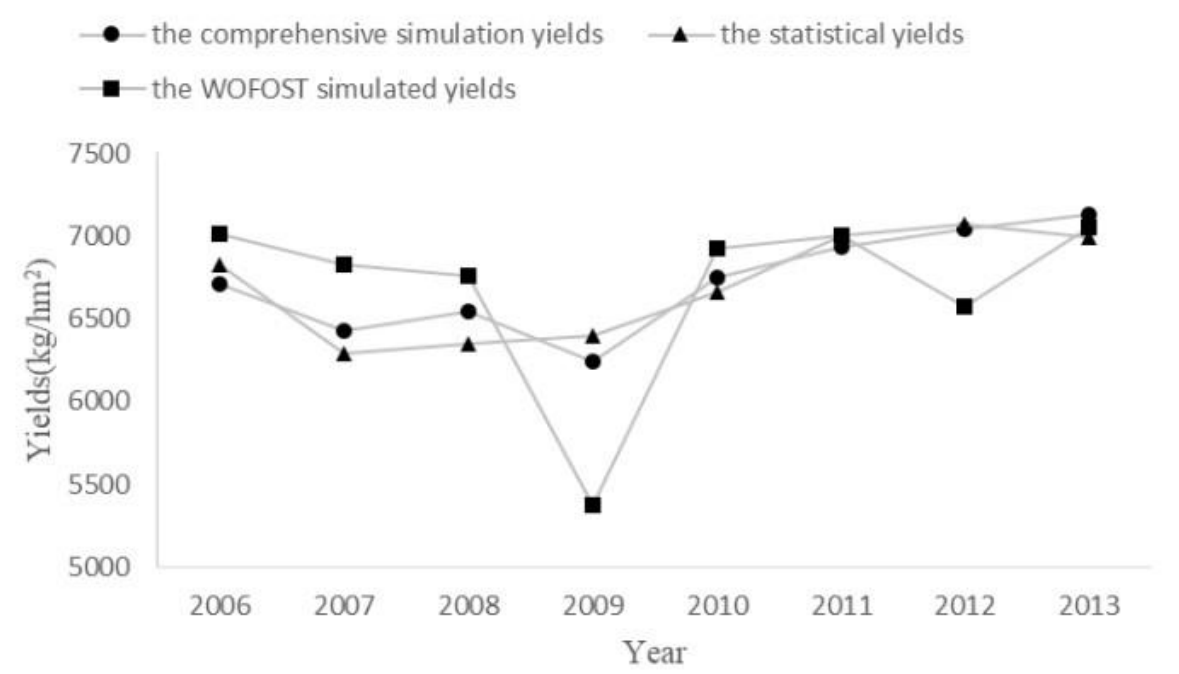

Fig.5. Comparison of the comprehensive simulated yield, the WOFOST yield and statistical yield at province scale in Heilongjiang Province from 2006 to 2013

\section{Conclusion}

First, the Heilongjiang Province rice growth observed data, contemporary observed meteorological data, and the local actual grow situation were all used to improve the rice parameter in WOFOST and simulated the rice yield in Heilongjiang Province. Then, combining the trend yield and WOFOST simulated yield, the comprehensive rice yield simulation model was estimated in Heilongjiang from 2006 to 2013 year by year. Finally, the results were analyzed both in county and province scale. The conclusions were as follows.

1)The combined crop parameters, TBASE,TSUM1, and TSUM2, were used to run the WOFOST model in large area, which can overcome the default that using the unified parameters set in complex climate area and broad the application of the model to large complex area.

2) Because of the low spatial resolution of the input parameters, such as meteorology, crop, and management and so on, which were caused by the limitation of data collecting in large area, the results of only using WOFOST model were not good. In county-wide, the correlation between WOFOST simulated and statistical yield is poor, and not passing the test of significance. In province-wide, the difference percentage between WOFOST simulated and statistical yield during 2006-2013 were respectively $2.71 \%, 8.47 \%, 6.41 \%,-15.96 \%, 3.95 \%, 0.02 \%,-7.06 \%, 0.88 \%$. Most years of them were similar, with several years the error were big.

3) In county scale, the comprehensive simulated yield and the statistical yield in county scale passed significant test of 0.01 , and the correlation coefficients were respectively $0.715,0.728,0.829,0.810,0.888,0.919,0.868,0.798$, the $\mathrm{R}^{2}$ were respectively $0.511,0.529,0.686,0.656,0.789,0.844,0.753,0.636$. In province scale, the error percentage between the eight year's estimated yield and statistical yield were respectively $-1.72 \%, 2.12 \%, 3.02 \%,-2.45 \%, 1.27 \%$, $0.89 \%,-0.38 \%, 1.96 \%$. The comprehensive model had a good effect on improving 
the defects of fluctuation in individual year with a relative higher accuracy than that of only using WOFOST model, and can satisfy the application of rice yield estimation in large region.

\section{Acknowledgment}

Funds for this research was supported by the Innovation Team of Crop Monitoring by Remote Sensing(CMIT), in Chinese Academy of Agricultural Engineering(CAAE) and was supported by the National Key R\&D Program of China(2016YFB0501505).

\section{References}

1. Yuping Ma, Shili Wang, Li Zhang. Study on improvement of WOFOST against overwinter of wheat in North China[J].Chinese Journal of Agrometeorology, 2005,26(3):145-149.

2. Supit I,Hooijper A A,van Diepen C A, et al. System Description of WOFOST6.0 Crop Simulation Model Implemented in CGMS[M], Theory and algorithms. Wagenningen, Netherlands: The Winand Starting Center for Intergrated Land, Soil and Water Research(SC-DLO), 1994:1-144.

3. Dingrong $\mathrm{Wu}$, Yangzhu Ou, Xiaomin Zhao et al.The applicability research of WOFOST model in North China plain[J]. Acta Phytoecologica Sinica, 2003,27(5):594-602.

4. Xie Wenxia,Yan Lijiao,Wang Guanghuo. Simuation and validation of rice potential growth process in Zhejiang by utilizing WOFOST model[J].Chinese Journal of Rice Science, 2006,20(3):319-323.

5. Zhenlin Chen, Jianping Zhang, Chunyi Wang et al. Application of WOFOST model in simulation of integrated impacts of low temperature and drought on maize yield[J]. Chinese Journal of Agrometeorology, 2007,28(4):440-442

6. Yuping Ma, Shili Wang, Li Zhang et al. A preliminary study on a regional growth simulation model of winter wheat in North China based on scaling-up approach I potential production level[J]. Acta Agronomica Sinica, 2005,31(6):697-705.

7. Xiufen Li, Yuguang Wang, Shengtai Ji et al. Validation of crop growth monitoring system(CGMS) in Heilongjiang province[J]. Chinese Journal of Agrometeorology, 2005, 26(3):155-157.

8. Gao Yonggang,Wang Yuguang, Yin Shiping et al.The application of World Food Study Model(WOFOST) for yield prediction in Heilongjiang province[J]. Chinese Journal of Agrometeorology, 2006, 27(1):27-30.

9. Du Chunying, Li Jifen, Wang Chenyi et al. Study on dynamic yield forecasting of rice based on WOFOST model in Heilongjiang province[J]. Journal of Anhui Agri Sci 2011, 39(24):15093-15095,15122.

10. Wang Yuguang,Li Xiufen,Du Chunying et al. Application of Belgium crop growth monitoring system in Heilongjiang province[J].Heilongiiang Meteorology,2003,3:9-11.

11. Bai Mingqi,Gao Yonggang,Wang Fang. Effect of temperature change on rice yield in Heilongjiang province[J]. Journal of Anhui Agri Sci 2008,36(31): 13571-13573,13580.

12. Liao Xiyuan. Rice region target yield production technology specification[J]. Beijing: China's agricultural science and technology press, 2010.

13. China Meteorological Data Sharing Service System[Z]. http://cdc.cma.gov.cn/home.do

14. Luo Li,Wang Xiaolei,Yu Peng.The compare and research of the calculate formula of the saturation water steam pressure[J].Meteorological, Hydrological and Marine Instruments, 2003(4):24-27.

15. B. Baruth, G. Genovese, O. Leo et al. CGMS version 9.2 User manual and technical documentation[M]. Institute for the Protection and Security of the Citizen (IPSC/JRC) and Alterra - Wageningen University and Research Centre, 2003.

16. Harmonized World Soil Database[Z]. http://www.fao.org/nr/land/soils/harmonized-worldsoil-database/download-data-only/en/

17. Wei Huaibin, Zhang Zhanpang, Yang Jinpeng. Establishing method for soil database of SWAT model[J].2008,38(6):15-18.

18. Zhang Li,Zhang Baohua. Analysis of meteorological yield of winter wheat[J],Chinese Journal of Agrometeorology, 2004,25(1):22-24. 